\title{
Quality of life of Chinese urologists: a cross- sectional study using WHOQOL-BREF
}

\author{
YB Wei, Z Yin, YL Gao, B Yan, Z Wang, JR Yang *
}

This article was published on $13 \mathrm{Feb}$ 2015 at www.hkmj.org.

\section{A B S T R A C T}

Objectives: In recent years, Chinese hospital settings are under violent threats. The exact status of quality of life of Chinese doctors under these disastrous situations remains obscure. The aim of this study was to assess the quality of life of Chinese urologists and analyse its potential affecting factors.

Design: Cross-sectional survey.

Setting: Beijing, China.

Participants: Overall, 1000 participants from more than 30 areas of China, who participated in the 20th National Urology Conference in Beijing in 2013, were surveyed. The brief version of the World Health Organization Quality of Life (WHOQOL-BREF) Chinese version was used to assess the quality of life among these urologists. The relationship between quality of life and the affecting factors was analysed.

Results: Of the 1000 questionnaires, 856 were completed and returned, and 708 questionnaires were valid for analysis. Approximately $46 \%$ of the respondents came from provincial capitals, $54.2 \%$ of them felt stress from medical environment, while $76.0 \%$ felt stress from research work, and $85.3 \%$ from promotion. Cronbach's $\alpha$ coefficient of the instrument was 0.825 , Kaiser-Meyer-Olkin measure was 0.841, and $P$ value of Bartlett's sphericity was $<0.001$. The results of binary logistic regression indicated gender,

affecting factors of quality of life only influenced one domain. In contrast, research work and promotion influenced three domains of the WHOQOL-BREF.

Conclusions: The study indicated that the WHOQOL-BREF may be a reliable and valid tool to assess quality of life of Chinese urologists. In China it is true that the deteriorative medical environment negatively affects medical practice according to previous studies, and policies are recommended to improve the situation. Nevertheless, we should not be too pessimistic about it, as in today's context research work and promotion may be the most extensive and significant affecting factors on doctors' quality of life.

\section{Hong Kong Med J 2015;21:232-6}

DOI: $10.12809 / \mathrm{hkmj} 144297$

\section{1,2 YB Wei, MD \\ ${ }^{1} \mathrm{Z}$ Yin, MD \\ ${ }^{1}$ YL Gao, MD \\ ${ }^{1} B$ Yan, MD \\ ${ }^{1}$ Z Wang, MD \\ ${ }^{1}$ YR Yang *, PhD}

1 Department of Urology, The Second Xiangya Hospital, Central South University, Changsha 410011, China

Department of Urology, Fujian Provincial Hospital, The Teaching Hospital of Fujian Medical University, Fuzhou 350001, China

work years, and medical environment as potential * Corresponding author: yjinrui2012@163.com

\footnotetext{
New knowledge added by this study

The brief version of the World Health Organization Quality of Life (Chinese version) may be reliable and valid to assess quality of life of Chinese urologists.

Implications for clinical practice or policy

- The policy-makers should pay attention to Chinese urologists' quality of life.
}

\section{Introduction}

In recent years, cases of Chinese hospital settings under violent threats have been reported and such reports have become the subject of worldwide attention. ${ }^{1,2}$ These adverse events have affected doctors and medical students in China. ${ }^{3,4}$ Violence against medical staff is not solely limited to China, but a worldwide issue..$^{5-7}$ Nevertheless, it is unimaginable that this kind of violence could become exacerbated, and this threat has even influenced the medical education of the future Chinese generation. As the lack of trust and relationship between doctors and patients in China becomes worse, many doctors are discontented and concerned about their safety during daily work. The survival status of Chinese doctors in this special period is worthy of attention. As of now, the exact status of Chinese doctors' quality of life (QOL) under conditions like these disastrous situations remains obscure.

A brief version of the World Health Organization Quality of Life (WHOQOL-100; WHOQOL-BREF) is one of the best known and acceptable instruments available. It has been developed for cross-cultural comparison of QOL and is available in more than 
40 languages. Its validity has been confirmed in assessing the subjective QOL of patients and the general public. The Chinese version of WHOQOLBREF has also proven to be reliable and valid in the assessment of QOL in Chinese individuals. ${ }^{8,9}$

The aim of this study was to assess the QOL of Chinese urologists from a nationwide survey ${ }^{10}$ to explore the possible influencing factors of QOL, and to generate public attention on the issue of QOL of the current medical community.

\section{Methods}

\section{Ethics statement}

The approval for this study was obtained from the Institutional Review Board of the Second Xiangya Hospital, Central South University, China. The survey was anonymous and questionnaires did not contain information that could identify individual respondents. The administrator saved all the returned questionnaires and data drawn from the survey remained confidential.

\section{Subjects}

The survey was carried out at the 20th National Urology Conference in Beijing held between 19 and 21 December $2013 .{ }^{10}$ The conference was organised by the Chinese Urological Association and was held at the China National Convention Center in Beijing. More than 2000 members registered for the conference from over 30 areas, which included participants from different provinces, cities, and autonomous regions of China. This cross-sectional study was conducted on 19 December 2013. A total of 1000 questionnaires were sent to the delegates and none of them reported repeating the test. Four welltrained investigators distributed and carried out the survey simultaneously and each survey process was limited to less than 10 minutes per participant. If participants had any questions regarding the survey, they could ask for help at any time during the process. The exclusion criteria were: (1) if more than $20 \%$ of items (5 items) were not answered in the WHOQOL-BREF questionnaire; or (2) if more than two items were not answered in the general information section, except the items of WHOQOLBREF.

\section{Survey instrument}

The questionnaire comprised two sections: (a) general information of respondents which included gender, professional qualifications (titles), working years, hospital location, and sources of stress including medical environment (referring to working environment and workplace safety), clinical work, research work, and promotion; and (b) the Chinese version of WHOQOL-BREF which consisted of 26 items in four domains. The four domains included

\section{中國大陸泌尿外科醫生的生活質量：使用世界衛 生組織生活質量 (簡潔版) 的橫斷面研究 \\ 魏永寶、尹焯、高雲亮、嚴涁、王釗、楊金瑞}

目的：近年來, 中國大陸醫療場所受到暴力威脅。在這個災難性的環 境下, 中國大陸醫生的生活質量如何尚未清楚。本研究旨在評估中國 大陸泌尿外科醫生的生活質量, 並分析其可能的影響因素。

設計：橫斷面研究

安排：中國北京。

參與者：問卷調查於2013年在北京舉行的第二十屆全國泌尿外科年會 期間進行, 參與者包括來自國內30多個地區共1000名與會人士。研究 採用中國版世界衛生組織生活質量（簡潔版）（WHOQOL-BREF） 量表來測評他們的生活質量, 並且對影響生活質量的因素進行分析。

結果：共發出 1000 份問卷, 其中完成並收回 856 份, 我們分析了其中 的 708 份有效問卷。約 $46 \%$ 被訪者來自省會城市, $54.2 \%$ 被訪者對當前 醫療環境感到壓力, 而 $76.0 \%$ 和 $85.3 \%$ 分別對研究工作和升職稱感到壓 力。該量表的信度係數為 0.825 , KMO檢驗統計量為 0.841 , 巴式球 面性檢驗的P值少於 0.001 。二元邏輯迴歸分析結果顯示性別、工作年 期和醫療環境作為潛在的影響因素僅對生活質量其中一項範疇產生影 響, 而研究工作和升職卻對生活質量的三個範疇都有影響。

結論：該研究提示WHOQOL-BREF能夠客觀評估中國大陸泌尿外科 醫生的生活質量。根據已有報導, 在中國大陸當前惡化的醫療環境可 能對日常醫療實踐產生負面影響, 並且需要有效措施來改善這種狀 態。然而, 我們不應過於悲觀, 因為在當前環境下, 醫生們的研究工 作和升職壓力可能更廣泛和更顯著影響醫生的生活質量。

in the brief version of WHOQOL-100 were physical health (PHYS), psychological health (PSYCH), social relationships (SOCIAL), and environment (ENVIR). Each of the 26 items was assigned value scores of 1 to 5. The score for each domain was transformed into a linear scale from 0 to 100 , reflecting QOL which ranged from lowest to highest.

\section{Statistical analyses}

Software EpiData version 3.1 (The EpiData Association, Odense, Denmark) was used to establish the database. Double data entry was done and this was double-checked by two well-trained researchers until the results were exactly the same. Besides the questionnaires that were excluded, in the general information section of the valid questionnaires, all the missing values were replaced with medians (rounded), and for WHOQOL-BREF, the missing data were replaced with the series mean.

All the statistical analyses were performed with the Statistical Package for the Social Sciences (SPSS; Windows version 16.0; SPSS Inc, Chicago [IL], US). Cronbach's $\alpha$ was used to measure internal consistency ('reliability'), while Kaiser-Meyer-Olkin (KMO) measure and Bartlett's test were used to assess the validity of the instrument. Data in each domain 
of WHOQOL-BREF were divided into two grouping variables by its mean. Binary logistic regression was carried out to analyse impact factors. A P value of $<0.05$ was considered statistically significant.

\section{Results}

\section{Sample characteristics}

Of the 1000 questionnaires sent, 856 were completed and returned. Approximately 17\% (148/856) were excluded according to the exclusion criteria. Among the remaining 708 questionnaires, the total missing data in the general information section and WHOQOL-BREF section were about 2.1\% (15/708) and about $3.0 \%(21 / 708)$, respectively, and these were considered to be valid. Of the 708 respondents, 597 (84.3\%) were male, and 111 (15.7\%) were female. The work years was divided into groups of $<10,10-19$, $20-29$ and $\geq 30$ years which was composed of $35.9 \%$, $35.5 \%, 18.4 \%$ and $10.2 \%$ of respondents, respectively. Approximately $46 \%$ of the respondents came from provincial capitals like Guangzhou in Guangdong province, and municipality directly under the central government like Shanghai. The professional qualifications (titles) were subdivided into three categories: junior, intermediate, and senior titles. From the start of career as a doctor in China, doctors work approximately 5 years to get promoted from each title level to the subsequent one. In the survey, almost half the respondents held senior professional titles. With regard to stress, all the four sources of stress had two options to choose from: 'Yes' and 'No'. For example, choosing 'Yes' in medical environment meant that respondents felt stress from medical environment, while choosing 'No' meant feeling no stress from this aspect. Each respondent could choose one or more than one source of stress. The results with regard to source of stress showed that $54.2 \%$ (384) felt stress from medical environment,

TABLE I. Results of binary logistic regression on affecting factors of quality of life of Chinese urologists

\begin{tabular}{lcccc}
\hline Variable & $\begin{array}{c}\text { Physical } \\
\text { health }\end{array}$ & $\begin{array}{c}\text { Psychological } \\
\text { health }\end{array}$ & $\begin{array}{c}\text { Social } \\
\text { relationships }\end{array}$ & Environment \\
\hline Gender & $*$ & $\dagger$ & $\dagger$ & $\dagger$ \\
Work years & $\dagger$ & $\dagger$ & $\dagger$ & $*$ \\
Title & $\dagger$ & $\dagger$ & $\dagger$ & $\dagger$ \\
Hospital location & $\dagger$ & $\dagger$ & $\dagger$ & $\dagger$ \\
Source of stress & & & & \\
$\quad$ Medical environment & $\dagger$ & $\dagger$ & $\dagger$ & $*$ \\
$\quad$ Clinical work & $\dagger$ & $\dagger$ & $\dagger$ & $\dagger$ \\
$\quad$ Research work & $*$ & $*$ & $*$ & $\dagger$ \\
$\quad$ Promotion & $*$ & $*$ & $\dagger$ & $*$ \\
\hline
\end{tabular}

* On behalf of affecting factors, all $P<0.05$

+ On behalf of non-affecting factors, all $P>0.05$
45.1\% (319) from clinical work, 76.0\% (538) from research work, and $85.3 \%$ (604) from promotion.

\section{Reliability and validity}

Reliability and validity were performed by SPSS. Cronbach's $\alpha$, the most common measurement of reliability, was used to assess the degree of internal uniformity. The overall Cronbach's $\alpha$ coefficient of the instrument was 0.825 , indicating the questionnaire was of good quality. Exploratory factor analysis is a mature and effective method used to uncover the underlying structure of a relatively large set of variables. Results showed that KMO measure was 0.841 and P value of Bartlett's sphericity was $<0.001$, indicating that the data gathered from the study were suitable for factor analysis.

\section{Quality of life according to affecting factors}

We then analysed the factors affecting each domain using binary logistic regression. Gender, titles, work years, hospital locations, and four sources of stress were entered as independent factors into the regression model. The analysis was performed by the Enter method. The Hosmer-Lemeshow test for the four regression equations were obtained: PHYS $(\mathrm{P}=0.198), \mathrm{PSYCH}(\mathrm{P}=0.863)$, SOCIAL $(\mathrm{P}=0.246)$, and ENVIR ( $\mathrm{P}=0.959)$, indicating higher fitting degrees. Affecting factors are presented in detail in Table 1 and their relative risks and 95\% confidence intervals are listed in Table 2 . Three factors that affected PHYS domain were found to be gender, research work, and promotion. Research work and promotion were also the two affecting factors of PSYCH domain. In the domain of SOCIAL, only research work proved to be an affecting factor. In the ENVIR domain, three factors were found affecting-work years, medical environment, and promotion. All the above affecting factors were significant with $P$ values of $<0.05$. The above results suggested that gender, work years, and medical environment were potential affecting factors of QOL and only influenced one domain. In contrast, research work and promotion influenced three domains of WHOQOL-BREF. Title, hospital location, and clinical work were demonstrated as non-affecting factors of four domains of WHOQOLBREF (all P>0.05).

\section{Discussion}

The reliability and validity of the WHOQOL-BREF instrument in a specialised Chinese population were analysed. The WHOQOL-BREF is used worldwide to assess QOL of different populations. The result suggests that the instrument is feasible in the assessment of QOL of Chinese medical professionals like urologists. The QOL of Chinese medical students ${ }^{8}$ and urban community residents ${ }^{9}$ have been successfully assessed using the WHOQOL-BREF 
TABLE 2. Relative risks (RRs) and $95 \%$ confidence intervals $(\mathrm{Cls})$ of binary logistic regression showing affecting factors of quality of life of Chinese urologists

\begin{tabular}{|c|c|c|c|c|c|c|c|c|}
\hline \multirow[t]{2}{*}{ Variable } & \multicolumn{2}{|c|}{ Physical health } & \multicolumn{2}{|c|}{ Psychological health } & \multicolumn{2}{|c|}{ Social relationships } & \multicolumn{2}{|c|}{ Environment } \\
\hline & $\mathbf{R R}$ & $95 \% \mathrm{Cl}$ & $\mathbf{R R}$ & $95 \% \mathrm{Cl}$ & $\mathbf{R R}$ & $95 \% \mathrm{Cl}$ & $\mathbf{R R}$ & $95 \% \mathrm{Cl}$ \\
\hline Gender & 1.671 & $1.067-2.618$ & & * & & * & & * \\
\hline Work years & & * & & * & & * & 1.252 & $1.016-1.542$ \\
\hline \multicolumn{9}{|l|}{ Source of stress } \\
\hline Medical environment & & * & & * & & * & 0.717 & $0.516-0.996$ \\
\hline Clinical work & & * & & * & & * & & * \\
\hline Research work & 1.603 & $1.104-2.328$ & 1.645 & $1.137-2.381$ & 1.716 & $1.163-2.534$ & & * \\
\hline Promotion & 0.547 & $0.351-0.853$ & 0.576 & $0.366-0.908$ & & * & 0.476 & $0.300-0.757$ \\
\hline
\end{tabular}

* On behalf of non-affecting factors, all $P>0.05$

and these studies have also proved the reliability and validity of the Chinese version of WHOQOLBREF. ${ }^{8,9}$

Usually the QOL of patients and geriatric populations are monitored with consideration. However, less attention has been placed on the QOL of health care practitioners, even physicians themselves. It is necessary to emphasise the QOL of health care facilitators when catastrophic events happen to medical staff. The QOL of health care providers (including physicians, nurses, and technicians) has been studied after the 2010 Haiti earthquake, and results suggest that health care providers have expressed dissatisfaction about their environment. ${ }^{11}$ In recent years, violence in health care settings in China has becoming increasingly fierce. More and more physicians and nurses have encountered physical attacks, light injuries resulting in psychological problems, or severe harm leading to death or disability. Living with high amounts of tension and fear, the work environment and personal life of Chinese medical staff are severely affected according to previous studies, ${ }^{2,12}$ In these situations, the QOL of Chinese physicians needs to be estimated. The study aimed to evaluate the QOL of Chinese urologists across the country.

In our study, 856 questionnaires were returned with a valid response rate of about $86 \%$ which is reasonable, and a total of 708 copies were used for final assessment. Males comprised the majority (84.3\%) which may be partially derived from the characteristics of field of urology, and because fewer females prefer being a surgeon, not to mention an urologist. It is known that Chinese medical staff's work environment and personal life are severely affected by violence happening in hospitals. ${ }^{1,2}$ In the four sources of stress in our study, only $54.2 \%$ of medical staff felt stress from medical environment, while $76.0 \%$ and $85.3 \%$ felt stress from research work and promotion, respectively. Following binary logistic regression analysis (Tables 1 and 2), titles, hospital locations, and clinical work were demonstrated as non-affecting factors in the four domains of WHOQOL-BREF (all P>0.05), indicating that these three variables may have very limited impact on doctors' QOL in today's world. When considering hospital location as an example, this information may provide a powerful and useful reference for recently graduated medical students in their job search. As in recently, most medical students tend to work in big cities, ${ }^{13}$ and our result indicated that the QOL of doctors living in provincial capitals and municipality directly under the central government may not be better than the other two city types, even though they might have better opportunities for further study, better life, and convenience which are driving their choice to work in big cities.

Like medical students, ${ }^{8}$ gender, work years, and medical environment proved as potential affecting factors of QOL but only influenced one domain of WHOQOL-BREF. In contrast, research work and promotion influenced three domains. These results suggest that research work and promotion might be the two most considerable sources of stress to Chinese doctors. As in recent China, with economic and technological take-off, especially the huge advances in modern medicine, Chinese doctors have to seize the opportunity and redouble their efforts to meet the challenges. Besides daily clinical work, they usually have to deal with extensive research work, and only then will they get promoted and paid well. Combining the above percentage of delegates choosing medical environment as a source of stress, it seems that although the medical environment has become worse and negatively impacts Chinese medical practice, it has not made such a powerful or deep influence to urologists' QOL, when compared with a wider and subtle impact of research work and promotion. Nevertheless, the side-effects of deteriorating medical environment on doctors should not be ignored, as it indeed negatively affects 
QOL of medical staff and medical education even in the next generation. ${ }^{2,3}$ The policy-makers in China should pay more attention to protect medical staff from violent threats during medical practice and policies to improve the situation are recommended.

This study has some limitations. First, selection and response bias might exist as the survey was done using convenience sampling, was self-reported, only urologists were investigated, and no comparison on the time span and other medical specialties were analysed. Second, other factors which might affect QOL and also be associated with the factors were not included and analysed in this study.

\section{Conclusions}

The study indicated that the WHOQOL-BREF may be a reliable and valid QOL assessment tool for Chinese urologists. It is true that the deteriorative medical environment negatively affects medical practice in China according to previous studies and policies are recommended to improve the situation. We, however, should not be too pessimistic about it, as in today's context research work and promotion may be the most extensive and significant affecting factors on doctors' QOL.

\section{Acknowledgements}

The study was supported by the Fundamental Research Funds for the Central Universities of Central South University in 2013 (no. 2013zzts095). The authors are grateful to the participants in the conference who took time to complete the survey.

\section{Declaration}

No conflicts of interest were declared by authors.

\section{References}

1. Huang J, Yan L, Zeng Y. Facing up to the threat in China. Lancet 2010;376:1823.

2. Sun S, Wang W. Violence against Chinese health-care workers. Lancet 2011;377:1747.

3. Jie L. New generations of Chinese doctors face crisis. Lancet 2012;379:1878.

4. Zeng J, Zeng XX, Tu Q. A gloomy future for medical students in China. Lancet 2013;382:1878.

5. Fernandes CM, Bouthillette F, Raboud JM, et al. Violence in the emergency department: a survey of health care workers. CMAJ 1999;161:1245-8.

6. Friedrich MJ. Human rights report details violence against health care workers in Bahrain. JAMA 2011;306:475-6.

7. Kowalenko T, Hauff SR, Morden PC, Smith B. Development of a Data Collection Instrument for Violent Patient Encounters against Healthcare Workers. West J Emerg Med 2012;13:429-33.

8. Zhang Y, Qu B, Lun S, Wang D, Guo Y, Liu J. Quality of life of medical students in China: a study using the WHOQOLBREF. PLoS One 2012;7:e49714.

9. Xia P, Li N, Hau KT, Liu C, Lu Y. Quality of life of Chinese urban community residents: a psychometric study of the mainland Chinese version of the WHOQOL-BREF. BMC Med Res Methodol 2012;12:37.

10. Special report one: the Twentieth National Urology Conference in 2013 opens today. 2013. Available from: http://www.ynurol.com/ct_show.asp?id=557. Accessed 6 Jan 2015.

11. Haar RJ, Naderi S, Acerra JR, Mathias M, Alagappan K. The livelihoods of Haitian health-care providers after the January 2010 earthquake: a pilot study of the economic and quality-of-life impact of emergency relief. Int J Emerg Med 2012;5:13.

12. Huang SL, Ding XY. Violence against Chinese health-care workers. Lancet 2011;377:1747.

13. Xinhua: High salary and housing cannot attract medical students; candidate students prefer big cities [in Chinese]. 2009. Available from: http://news.xinhuanet.com/edu/200911/24/content_12528605.htm. Accessed 23 Jan 2014. 